Portland State University

PDXScholar

\title{
Biomechanical Analysis of Concealed Pack Load Influences on Terrorist Gait Signatures Derived from Gröbner Basis Theory
}

\author{
Sean S. Kohles \\ Portland State University \\ Anum Barki \\ Air Force Institute of Technology \\ Kimberly D. Kendricks \\ Central State University \\ Ronald F. Tuttle \\ Air Force Institute of Technology
}

Follow this and additional works at: https://pdxscholar.library.pdx.edu/bio_fac

Part of the Biomechanics and Biotransport Commons

Let us know how access to this document benefits you.

\begin{abstract}
Citation Details
Kohles SS, Barki A, Kendricks KD, Tuttle RF (2014) Biomechanical Analysis of Concealed Pack Load Influences on Terrorist Gait Signatures Derived from Gröbner Basis Theory. Forensic Biomechanics 5: 104.
\end{abstract}

This Article is brought to you for free and open access. It has been accepted for inclusion in Biology Faculty Publications and Presentations by an authorized administrator of PDXScholar. Please contact us if we can make this document more accessible: pdxscholar@pdx.edu. 


\title{
Journal of Forensic Biomechanics
}

\section{Biomechanical Analysis of Concealed Pack Load Influences on Terrorist Gait Signatures derived from Gröbner Basis Theory}

\author{
Sean S Kohles ${ }^{1^{*}}$, Anum Barki ${ }^{2}$, Kimberly D. Kendricks ${ }^{3}$ and Ronald F. Tuttle ${ }^{4}$ \\ ${ }^{1}$ Affiliate Professor Division of Biomaterials \& Biomechanics Department of Restorative Dentistry Oregon Health \& Science University Portland. \\ ${ }^{2}$ Research Assistant Department of Engineering Physics Air Force Institute of Technology, Wright Patterson Air Force Base. \\ ${ }^{3}$ Associate Professor Department of Mathematics and Computer Science Center for Human Performance and Sensor Applications Central State University Wilberforce. \\ ${ }^{4}$ Associate Professor Department of Engineering Physics Air Force Institute of Technology, Wright Patterson Air Force Base.
}

*Corresponding author: Sean S. Kohles, Affiliate Professor Division of Biomaterials \& Biomechanics Department of Restorative Dentistry Oregon Health \& Science University Portland, OR 97239 USA, Tel: 5035167528; E-mail: kohles@ohsu.edu

Received on: March 24, 2014; Accepted on: October 07, 2014; Published on: October 14, 2014

Copyright: (C) 2014 Kohles S, et al. This is an open-access article distributed under the terms of the Creative Commons Attribution License, which permits unrestricted use, distribution, and reproduction in any medium, provided the original author and source are credited.

\begin{abstract}
This project examines kinematic gait parameters as forensic predictors of the influence associated with individuals carrying concealed weighted packs up to $20 \%$ of their body weight. An initial inverse dynamics approach combined with computational algebra provided lower limb joint angles during the stance phase of gait as measured from 12 human subjects during normal walking. The following paper describes the additional biomechanical analysis of the joint angle data to produce kinetic and kinematic parameters further characterizing human motion. Results include the rotational velocities and accelerations of the hip, knee, and ankle as well as inertial moments and kinetic energies produced at these joints. The reported findings indicate a non-statistically significant influence of concealed pack load, body mass index, and gender on joint kinetics ( $p>0.05)$. Ratios of loaded to unloaded kinematics, however, identified some statistical influence on gait $(p<0.05)$. On-going studies are examining an additional subject cohort with greater pack loads in an effort to identify alterations in gait signatures as a counter-terrorism approach.
\end{abstract}

Keywords: Biomechanics; Kinesiology; Counter-terrorism; Gait parameters; Concealed pack loads; Inverse dynamics

\section{Introduction}

Suicide bombings have become an increasing threat to civilians and military personnel in Middle Eastern countries. In a recent study that documented civilian casualties from suicide attacks during the Iraq War from 2003 to 2010, over thirty thousand civilian injuries and over twelve thousand civilian deaths were caused by such bomb events [1]. The article also reported deaths of 200 coalition troops of which 175 were members of the United States military. An online database has also documented the reported deaths of Iraqi civilians from the first day of the Iraq War [2]. Overall, as of December 17, 2012 an average of 7.5 civilians have died each day due to 'terror attacks' in Iraq, demonstrating threat to civilian and military personnel. To address this threat, biometrics such as fingerprint, face, iris, and gait data have been used successfully to identify suspicious individuals [3-6]. Of these, gait is the least intrusive, and can be studied using video surveillance at a distance. However, gait characteristics are more difficult to identify and isolate when compared to fingerprints or facial features [7]. As a response to these challenges, the investigation into human gait characteristics for the purpose of developing an automatic human identification system was initiated through the INSPIRE project (Integration of a Sensor Package for Identifying Radical Extremists). One of the objectives within INSPIRE is to design a suicide bomber vetting system that is able to screen individuals 150 to $300 \mathrm{~m}$ away from a military or civilian checkpoint through the use of video captured data. The goal in the present work is to measure and identify human gait characteristics within a controlled laboratory setting that may be used as a possible 'gait signature' for an individual carrying a concealed detonation device having recognizable weight.

The human eye is sensitive to motion stimuli and can detect the gait characteristics of familiar individuals such as family and friends, particularly in crowds $[8,9]$. Yet, it is not clear what gait markers the human visual system is using for individual identification. An aim of this issue is to isolate motion perception to determine these gait markers. Research studies using point-light displays of human motion have demonstrated improvements in identifying observed motion characteristics, and the reliability of these observations has increased [10-12].

This study addresses this issue by examining the data collected from point-light displays of the lower extremities when additional load is carried on the body to identify altered markers in the gait cycle. This effort further examines the mechanics of extension and flexion of the lower extremity joints during human motion beyond that previously reported [13]. The anatomic functions that have been analyzed include extension and flexion at the hip and knee joint well as plantar and dorsi flexion at the ankle joint. A three-link, segmental model has provided a simplified arrangement to examine human dynamic walking, a biped gait pattern which is considered dynamically stable [14]. The application of a rigid-body dynamics analysis has been shown to effectively facilitate the description of human motion, which is periodic, stable, and energy efficient. The human body represents a well-balanced walking machine with highly sophisticated mechanics and control. The working hypothesis in this investigation is that the controlled motion of gait can be perturbed when individuals wear concealed and weighted packs, when compared to a no-load condition. In reality, most terrorist subjects would likely not be identified during the no-load condition. The objective here is to validate the sensitivity 
in this analytical approach by defining the key mechanics of lower limb motion, which may be used as markers indicating any gait perturbations caused by an increase in concealed pack loads.

\section{Materials and Methods}

\section{Data Collection}

Lower limb anatomic joint location data were collected from 12 healthy subjects between the ages of 21 and 42 ( 7 males and 5 females) using a three-dimensional motion capture system (MX T160 cameras and Nexus software, Vicon Motion Systems Ltd.). Subjects were instructed to ambulate at a comfortable, self-selected walking speed on a treadmill with zero incline (Figure 1), and based on a previous gait study [15]. Joint location data were tracked unilaterally through time at $30 \mathrm{~Hz}(\Delta \mathrm{t}=0.03 \mathrm{~s} /$ frame $)$ with reflective markers attached to skintight outer garments [16]. Each marker was carefully attached on the skin near a palpable bony prominence associated with the four lower limb joints of interest. These locations helped to reduce the noise that may be created by clothing or soft tissue artifacts [17,18]. Marker 1 was placed on the hip joint near the femoral greater trochanter, marker 2 was placed at the lateral fibular condyle near the knee joint, marker 3 was placed at the lateral malleolus near the talocrural ankle joint, and marker 4 was placed laterally near the metatarsalphalangeal joint at the head of the fifth metatarsal.

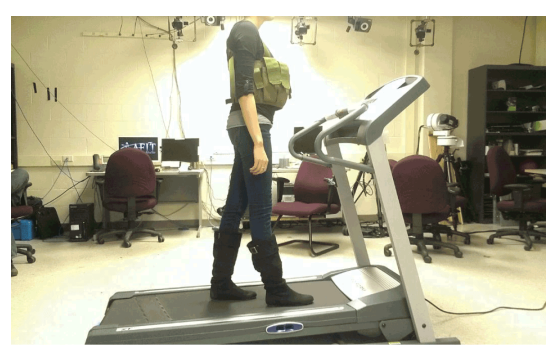

Figure 1: Representative image of a subject wearing a loaded ammunition pack while walking on the laboratory treadmill. There was no slope to the walking surface for this particular study $\left(0^{\circ}\right.$ incline setting). Note that the pack load is distributed about the subject's mid-section with front-load pockets, near their body center of mass (cm Body).

The subjects were instructed to walk for ten gait cycles leading up to a single measurement cycle (average walking speed range $=2.1$ to $3.6 \mathrm{mi} / \mathrm{h}$ or 0.94 to $1.61 \mathrm{~m} / \mathrm{s}$ ). Each subject wore a six-pocket vest representing a concealable pack design allowing for multiple weight distributions. The pack design and pack loads followed that of previous study examining sagittal plane stability during gait [19]. After the initial no-load trial, a $10 \%$ body weight (BW) load was added to the vest (Figure 1). Trials continued with each trial adding 5\% BW up to $20 \% \mathrm{BW}$ (maximum carried $=26 \mathrm{lbs}$ or $11.8 \mathrm{~kg}$ mass) as approved by the AFIT Institutional Review Board (IRB). Each subject experienced 2 to 4 total gait trials. Gait data were analysed from one representative stance phase during the gait cycle. The body mass index (BMI) was determined for each subject as a generalized metric of physical health such that BMI is equal to body mass (in $\mathrm{kg}$ ) divided by the square of the subject's height (in $\mathrm{m}$ ). A normal BMI range for adults is 18.5 to 24.9 [20].

\section{Joint Angle Determination from Gröbner Basis Theory}

A previously developed and validated gait model for lower $[13,16,21]$ and upper $[22,23]$ extremity limb motion was applied to the gathered joint position data. This model facilitated the analysis of joint angles through known limb segment lengths gathered from each subject (Figure 2). The inverse dynamics approach was applied through engaging Gröbner Basis Theory to a single stance-phase of the gait cycle (heel-touch to toe-off). Briefly, the Gröbner basis computation was introduced in 1965 as an algebraic tool for solving a set of non-zero polynomial equations [24]. The computation is a generalization of both Euclid's algorithm and Gaussian elimination [25]. The computational algorithm was applied here to a set of multivariate nonlinear equations having in common certain properties such as the linked anatomic geometries and motions captured during gait. This approach allowed for a simplified algebraic solution to the inverse kinematics problem as a preface to further biomechanical analyses described herein.

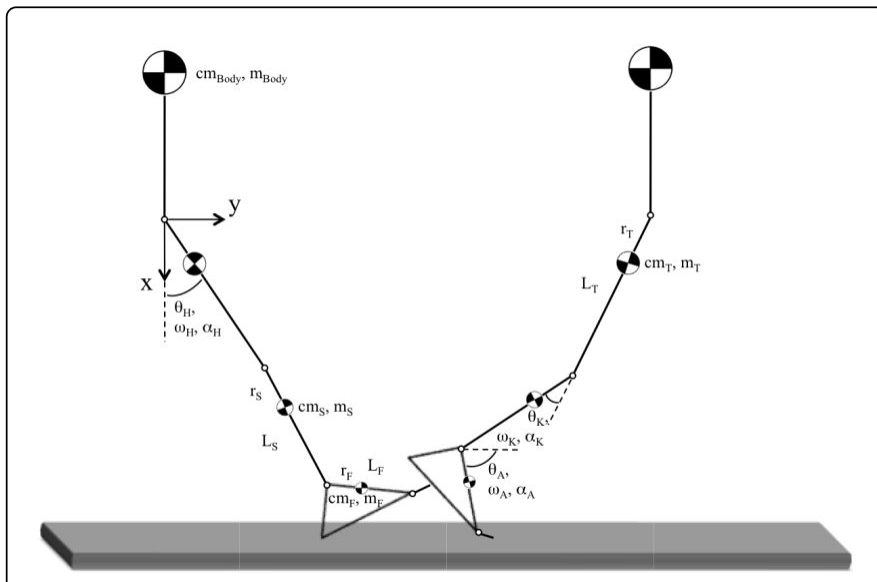

Figure 2: Schematic representing a single-limb, human multisegmental model during the heel-touch (left) to toe-off (right) phase of gait as analyzed in this work. Segmental lengths (Lk), masses (mk), centers of mass (cmk), and locations (rk) of each cmk are indicated along with the positive angular sign-conventions for displacement $(\theta j)$ and velocity $(\omega \mathrm{j})$ drawn relative to each respective joint datum (dashed lines).

\section{Joint Kinetic and Kinematic Analysis}

Euler rotational velocities $(\omega)$ and accelerations $(\alpha)$ about the horizontal $z$-axes ( $r-\theta$ polar coordinates defining the sagittal plane) through each of the lower limb joints were determined [26]. These kinematic parameters were calculated from the joint angular displacements ( $\Delta \theta$ in radians) and time data as determined from a previous Gröbner basis computation [16]. The calculations of angular velocity and accelerations were based on $2 \Delta \mathrm{t}$ instead of $\Delta \mathrm{t}$, so that the angular velocity $\left(\omega_{i}\right)$ and the angular acceleration $\left(a_{i}\right)$ at each $i^{\text {th }}$ sample were:

$$
\omega_{\mathrm{i}}=\left(\theta_{\mathrm{i}+1}-\theta_{\mathrm{i}-1}\right) / 2 \Delta \mathrm{t} \text { and } \alpha_{\mathrm{i}}=\left(\omega_{\mathrm{yi}+1}-\omega_{\mathrm{yi}-1}\right) / 2 \Delta \mathrm{t}
$$

where $\Delta t$ is the time between sequential motion capture frames and defined above as $0.03 \mathrm{~s}$.

The net reaction moments (joint, weight, and ground reaction) can be calculated by applying the rotational analogue of Newton's Second 
Citation: Kohles SS, Barki A, Kendricks KD, Tuttle RF (2014) Biomechanical Analysis of Concealed Pack Load Influences on Terrorist Gait Signatures derived from Gröbner Basis Theory. Forensic Biomechanics 5: 104. doi:10.4172/2090-2697.1000104

Page 3 of 8

Law of Motion $\left(\sum M=I \alpha\right)$. In this study, no ground reaction forces were gathered, thus the isolated joint moments themselves cannot be determined. However, the inertial moments for each $i^{\text {th }}$ time sample about each $j^{\text {th }}$ joint $\left(j=\right.$ hip, knee, ankle) can be defined for each $k^{\text {th }}$ limb segment $(\mathrm{k}=$ thigh, shank, foot $)$ as:

$$
\sum \mathrm{M}_{\mathrm{j}}=\mathrm{I}_{\mathrm{k}} \mathrm{a}_{\mathrm{i}}
$$

Based on percentile limb segment masses $\left(\mathrm{m}_{\mathrm{k}}\right)$ from which limb segment mass moments of inertia (I) can be calculated about each joint $[27,28]$. From the anthropometric data, the following values were calculated from published limb mass distributions [28] and related to polar reference axes with origins at either the hip, knee, or ankle joints (Figure 2): Mass of the thigh $\left(\mathrm{m}_{\mathrm{T}}\right)$; Mass of the shank $\left(\mathrm{m}_{\mathrm{S}}\right)$; Mass of the foot $\left(\mathrm{m}_{\mathrm{F}}\right)$; Lower limb total mass $\left(\mathrm{m}_{\mathrm{LL}}=\mathrm{m}_{\mathrm{T}}+\mathrm{m}_{\mathrm{S}}+\mathrm{m}_{\mathrm{F}}\right)$; Center of mass from the proximal limb end of the thigh $\left(\mathrm{cm}_{\mathrm{T}}\right)$; Center of mass from the proximal limb end of the shank $\left(\mathrm{cm}_{\mathrm{S}}\right)$; Center of mass from the proximal limb end of the foot $\left(\mathrm{cm}_{\mathrm{F}}\right)$; and the polar coordinate distances of the $\mathrm{cm}_{\mathrm{T}}, \mathrm{cm}_{\mathrm{S}}$, and $\mathrm{cm}_{\mathrm{F}}$ from the joint origins $\left(\mathrm{r}_{\mathrm{T}}, \mathrm{r}_{\mathrm{S}}\right.$, and $r_{F}$, respectively). The limb segment lengths were measured from each subject directly $\left(\mathrm{L}_{\mathrm{T}}, \mathrm{L}_{\mathrm{S}}\right.$, and $\left.\mathrm{L}_{\mathrm{F}}\right)$.

In the calculation of the mass moment of inertia for the lower limb segments, the non-uniformity of the limb and each segment was accounted for via the center of mass placements:

$$
I_{c m}=\int r^{2} d m=\int r^{2}\left(m_{k} / L_{k}\right) d r(3)
$$

The parallel axis theorem then allows for the moment of inertia to be calculated about any joint axis, where $D_{k}$ is the distance from the joint center of rotation to the $\mathrm{cm}_{\mathrm{k}}$ :

$$
I=\Sigma I_{c m_{k}}+\Sigma m_{k} D_{k}^{2}(4)
$$

Here, the summation indicates that each distal segment will contribute to the inertia about the proximal joint, i.e., the hip joint mechanics are influenced by the inertia of the thigh, knee, and foot, etc.

Upon determination of the limb segment inertia, rotational kinetic energies (KE), which can be derived from the integration of the inertial moment in equation (2), were also determined for each joint at each time increment throughout the entire stance phase:

$$
K E_{j}=\frac{1}{2} I j \omega_{i}^{2}(5)
$$

Thus, directly incorporating the rotational velocity kinematics.

\section{Statistical Analysis}

Extrema kinematic parameters were identified during functional joint motion and used to calculate the respective maxima (largest positive) and minima (largest negative) kinetic parameters. Descriptive and comparative statistics including analysis of variance (one-way, two-way and three-way ANOVAs) tested the statistical influence of the primary objective of pack weight on the kinetic and kinematic gait parameters during the repeated measures design. Missing data within the experimental design were accounted for within the ANOVAs. Kinematic parameters were normalized for each subject by their nonload trials and analysed in aggregate with a student's t-test (any-load : no-load distributions compared with a hypothesized mean=1.0). The statistical analysis was also applied to identify the strength of other independent variables (gender, BMI, and anatomic joint) as predictors of the dependent variables (joint angular position, angular velocities, rotational accelerations, inertial moments, and kinetic energy). All data/statistical analyses were conducted with commercial software (JMP v5.0.1, SAS Institute, Inc.). Statistical significance was considered when $\mathrm{p}<0.05$, with $\alpha=0.05$ minimizing Type I errors.

\section{Results}

All 12 subjects $($ mean $\mathrm{BMI}=23.33+/ 3.25$ sd) contributed to 36 total gait trials. Kinematic and kinetic parameters were determined for each anatomical joint at each time increment throughout the single

\begin{tabular}{|c|c|c|c|c|c|c|c|}
\hline \multirow{2}{*}{$\begin{array}{l}\text { Kinematic } \\
\text { Parameter }\end{array}$} & \multirow{2}{*}{$\begin{array}{l}\text { Load } \\
\text { (\%BW) }\end{array}$} & \multicolumn{2}{|c|}{ Hip Joint Ratios } & \multicolumn{2}{|c|}{ Knee Joint Ratios } & \multicolumn{2}{|c|}{ Ankle Joint Ratios } \\
\hline & & Max & Min & Max & Min & Max & Min \\
\hline \multirow{4}{*}{$\begin{array}{l}\text { Angular } \\
\text { Position }(\theta)\end{array}$} & & $p=0.0053$ & $p=0.2790$ & $p=0.0355$ & $p=0.0022$ & $p=0.1819$ & $p=0.5718$ \\
\hline & $10 \%$ & $1.05\{0.06\}$ & $1.01\{0.11\}$ & $1.03\{0.04\}$ & $1.40\{0.69\}$ & $4.67\{12.54\}$ & $0.94\{0.10\}$ \\
\hline & $15 \%$ & $1.02\{0.07\}$ & $1.02\{0.15\}$ & $1.01\{0.06\}$ & $1.46\{0.60\}$ & $1.52\{1.27\}$ & $1.01\{0.21\}$ \\
\hline & $20 \%$ & $1.05\{0.04\}$ & $1.14\{0.16\}$ & $1.02\{0.06\}$ & $1.40\{0.36\}$ & $4.34\{7.35\}$ & $1.04\{0.18\}$ \\
\hline \multirow{4}{*}{$\begin{array}{l}\text { Angular } \\
\text { Velocity }(\omega)\end{array}$} & & $p=0.8907$ & $p=0.1180$ & $p=0.7113$ & $p=0.0001$ & $p=0.0153$ & $p=0.3664$ \\
\hline & $10 \%$ & $1.02\{0.06\}$ & $1.03\{0.10\}$ & $0.99\{0.06\}$ & $1.06\{0.05\}$ & $1.05\{0.20\}$ & $1.00\{0.13\}$ \\
\hline & $15 \%$ & $0.97\{0.09\}$ & $1.02\{0.13\}$ & $0.97\{0.15\}$ & $1.04\{0.07\}$ & $1.20\{0.31\}$ & $1.05\{0.15\}$ \\
\hline & $20 \%$ & $0.98\{0.07\}$ & $1.11\{0.11\}$ & $1.05\{0.12\}$ & $1.11\{0.03\}$ & $1.20\{0.16\}$ & $1.06\{0.08\}$ \\
\hline \multirow{4}{*}{$\begin{array}{l}\text { Angular } \\
\text { Acceleration }(\alpha)\end{array}$} & & $p=0.0160$ & $p=0.0001$ & $p=0.0179$ & $p=0.1739$ & $p=0.0722$ & $p=0.0354$ \\
\hline & $10 \%$ & $1.05\{0.11\}$ & $1.14\{0.14\}$ & $1.16\{0.24\}$ & $1.05\{0.07\}$ & $1.00\{0.17\}$ & $1.06\{0.22\}$ \\
\hline & $15 \%$ & $1.05\{0.18\}$ & $1.14\{0.17\}$ & $1.09\{0.25\}$ & $0.99\{0.13\}$ & $1.08\{0.14\}$ & $1.13\{0.22\}$ \\
\hline & $20 \%$ & $1.32\{0.15\}$ & $1.18\{0.08\}$ & $1.12\{0.34\}$ & $1.04\{0.06\}$ & $1.17\{0.12\}$ & $1.16\{0.29\}$ \\
\hline
\end{tabular}
stance phase of gait. Means $+/$ standard deviations (sd) are presented in the tables and figures.

Table 1: All Subjects 
Citation: Kohles SS, Barki A, Kendricks KD, Tuttle RF (2014) Biomechanical Analysis of Concealed Pack Load Influences on Terrorist Gait

\section{Joint Kinematics}

The results from all combined subjects indicate a subtle influence of pack weight on the kinematic metrics of joint position, velocity, and acceleration compared with the no- load condition (Table 1). The ratios represent normalization with the no-load condition for each joint at each load condition. The stated p-values indicate statistical comparison with a hypothesized distribution mean of 1.0 as aggregated over all of the pack loads. A number of the maxima (left column) and minima (right column) kinematic results indicate a statistically significant difference from the no-load equivalence of 1.0 $(\mathrm{p}<0.05)$. However, multi-way ANOVAs consistently indicated no statistical influence of either pack load or BMI on gait kinematics $(\mathrm{p}>0.05)$.

\section{Joint Kinetics}

Findings from all combined subjects indicated little influence ( $>0.05$ ) of pack weight on either the inertial moments (Figure 3) or the kinetic energies (Figure 4).

A)

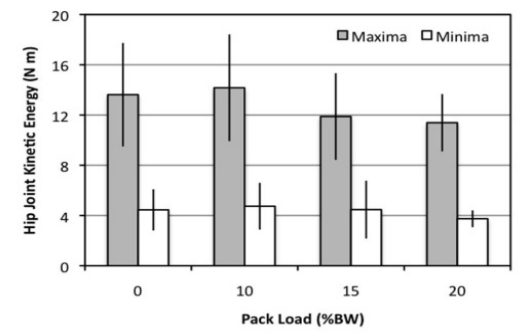

B)

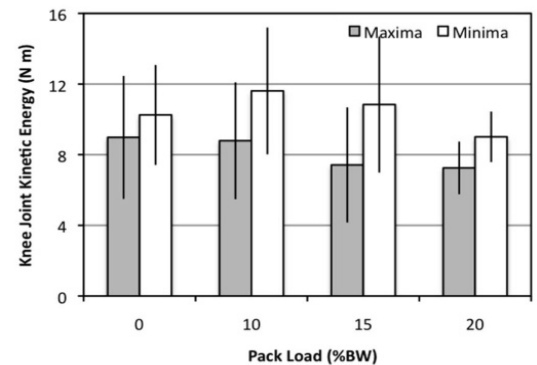

C)

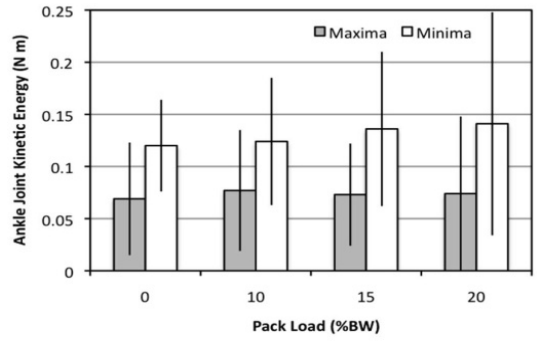

Figure 4: Mean kinetic energies $\{+/-s d\}$ plotted for all subjects over the range of pack loads as determined for the (A) hip, (B) knee, and (C) ankle joints. Note that kinetic energy is determined from the square of the peak angular velocities.
A)

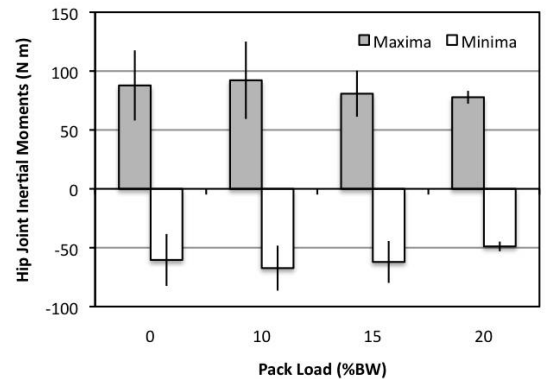

B)

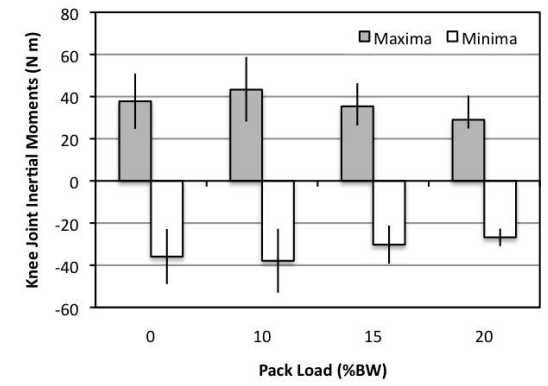

C)

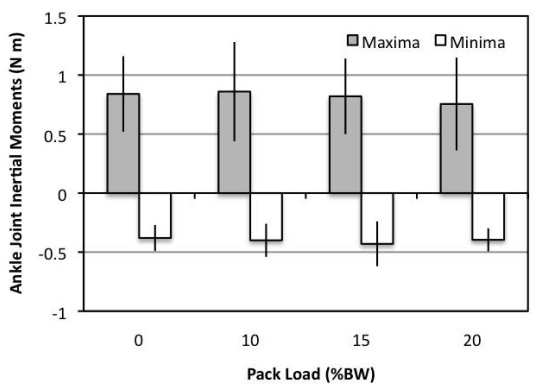

Figure 3: Mean inertial moments $\{+/-$ sd $\}$ plotted for all subjects over the range of pack loads as determined for the (A) hip, (B) knee, and (C) ankle joints.

These values were further tabulated separately for male (Table 2) and female (Table 3) subjects as means to explore any gender-dependent characteristics although no statistical difference in kinetics were shown $(\mathrm{p}>0.05)$. 
Citation: Kohles SS, Barki A, Kendricks KD, Tuttle RF (2014) Biomechanical Analysis of Concealed Pack Load Influences on Terrorist Gait

Page 5 of 8

\begin{tabular}{|c|c|c|c|c|c|c|c|}
\hline \multirow{2}{*}{$\begin{array}{l}\text { Kinetic } \\
\text { Parameters }\end{array}$} & \multirow{2}{*}{$\begin{array}{l}\text { Load } \\
\text { (\%BW) }\end{array}$} & \multicolumn{2}{|c|}{ Hip Joint } & \multicolumn{2}{|c|}{ Knee Joint } & \multicolumn{2}{|c|}{ Ankle Joint } \\
\hline & & $\operatorname{Max}$ & Min & $\operatorname{Max}$ & Min & $\operatorname{Max}$ & Min \\
\hline \multirow[t]{4}{*}{$\begin{array}{l}\text { Inertial Moment } \\
(\mathrm{N} \mathrm{m})\end{array}$} & $0 \%$ & $\begin{array}{l}99.32 \\
\{32.36\}\end{array}$ & $\begin{array}{l}63.79 \\
\{24.65\}\end{array}$ & $\begin{array}{l}44.43 \\
\{12.19\}\end{array}$ & $\begin{array}{l}41.05 \\
\{14.28\}\end{array}$ & $\begin{array}{l}0.88 \\
\{0.28\}\end{array}$ & $\begin{array}{l}0.39 \\
\{0.11\}\end{array}$ \\
\hline & $10 \%$ & $\begin{array}{l}102.26 \\
\{38.63\}\end{array}$ & $\begin{array}{l}72.51 \\
\{21.64\}\end{array}$ & $\begin{array}{l}50.14 \\
\{11.23\}\end{array}$ & $\begin{array}{l}43.06 \\
\{17.64\}\end{array}$ & $\begin{array}{l}0.94 \\
\{0.48\}\end{array}$ & $\begin{array}{l}0.44 \\
\{0.15\}\end{array}$ \\
\hline & $15 \%$ & $\begin{array}{l}92.49 \\
\{16.86\}\end{array}$ & $\begin{array}{l}-65.96 \\
\{23.70\}\end{array}$ & $\begin{array}{l}35.86 \\
\{11.48\}\end{array}$ & $\begin{array}{l}-34.25 \\
\{11.58\}\end{array}$ & $\begin{array}{l}0.80 \\
\{0.22\}\end{array}$ & $\begin{array}{l}-0.50 \\
\{0.24\}\end{array}$ \\
\hline & $20 \%$ & 83.92 & -44.87 & 41.70 & -22.28 & 0.53 & -0.31 \\
\hline \multirow[t]{4}{*}{$\begin{array}{l}\text { Kinetic Energy } \\
(\mathrm{N} \mathrm{m})\end{array}$} & $0 \%$ & $\begin{array}{l}13.45 \\
\{4.79\}\end{array}$ & $\begin{array}{l}5.07 \\
\{1.72\}\end{array}$ & $\begin{array}{l}9.92 \\
\{3.69\}\end{array}$ & $\begin{array}{l}11.29 \\
\{3.11\}\end{array}$ & $\begin{array}{l}0.06 \\
\{0.03\}\end{array}$ & $\begin{array}{l}0.12 \\
\{0.03\}\end{array}$ \\
\hline & $10 \%$ & $\begin{array}{l}14.82 \\
\{4.95\}\end{array}$ & $\begin{array}{l}5.39 \\
\{2.01\}\end{array}$ & $\begin{array}{l}9.76 \\
\{3.57\}\end{array}$ & $\begin{array}{l}12.54 \\
\{3.86\}\end{array}$ & $\begin{array}{l}0.08 \\
\{0.06\}\end{array}$ & $\begin{array}{l}0.13 \\
\{0.06\}\end{array}$ \\
\hline & $15 \%$ & $\begin{array}{l}12.05 \\
\{3.34\}\end{array}$ & $\begin{array}{l}5.38 \\
\{3.02\}\end{array}$ & $\begin{array}{l}8.92 \\
\{3.70\}\end{array}$ & $\begin{array}{l}12.08 \\
\{5.21\}\end{array}$ & $\begin{array}{l}0.05 \\
\{0.02\}\end{array}$ & $\begin{array}{l}0.11 \\
\{0.05\}\end{array}$ \\
\hline & $20 \%$ & 10.67 & 4.43 & 6.53 & 8.55 & 0.02 & 0.09 \\
\hline
\end{tabular}

Table 2: Mean kinetic joint parameters $\{+/-$ sd $\}$ calculated from male subject data $(n=7)$ of which each were carrying a range of pack loads as percentages of body weight. No variance was calculated for the $20 \%$ pack load level as data from only one subject were gathered.

Again, the split cells within the tables indicate the maxima (left) and minima (right) values generated by the subject during the analysed influence of BMI on joint kinetics, especially that of the inertial gait cycle. A three-way ANOVA did however indicate a statistical moments (Table 4).

\begin{tabular}{|c|c|c|c|c|c|c|c|}
\hline \multirow{2}{*}{$\begin{array}{l}\text { Kinetic } \\
\text { Parameters }\end{array}$} & \multirow{2}{*}{$\begin{array}{l}\text { Load } \\
\text { (\%BW) }\end{array}$} & \multicolumn{2}{|c|}{ Hip Joint } & \multicolumn{2}{|c|}{ Knee Joint } & \multicolumn{2}{|c|}{ Ankle Joint } \\
\hline & & Max & Min & $\operatorname{Max}$ & Min & $\operatorname{Max}$ & Min \\
\hline \multirow[t]{4}{*}{$\begin{array}{l}\text { Inertial Moment } \\
(\mathrm{N} \mathrm{m})\end{array}$} & $0 \%$ & $\begin{array}{l}71.70 \\
\{17.62\}\end{array}$ & $\begin{array}{l}55.60 \\
\{19.36\}\end{array}$ & $\begin{array}{l}28.46 \\
\{7.90\}\end{array}$ & $\begin{array}{l}28.68 \\
\{7.14\}\end{array}$ & $\begin{array}{l}0.78 \\
\{0.40\}\end{array}$ & $\begin{array}{l}0.36 \\
\{0.12\}\end{array}$ \\
\hline & $10 \%$ & $\begin{array}{l}78.10 \\
\{17.43\}\end{array}$ & $\begin{array}{l}60.06 \\
\{13.70\}\end{array}$ & $\begin{array}{l}33.73 \\
\{16.65\}\end{array}$ & $\begin{array}{l}30.66 \\
\{7.16\}\end{array}$ & $\begin{array}{l}0.74 \\
\{0.34\}\end{array}$ & $\begin{array}{l}0.34 \\
\{0.15\}\end{array}$ \\
\hline & $15 \%$ & $\begin{array}{l}71.44 \\
\{17.45\}\end{array}$ & $\begin{array}{l}58.98 \\
\{13.59\}\end{array}$ & $\begin{array}{l}35.01 \\
\{11.91\}\end{array}$ & $\begin{array}{l}27.03 \\
\{5.95\}\end{array}$ & $\begin{array}{l}0.84 \\
\{0.41\}\end{array}$ & $\begin{array}{l}0.37 \\
\{0.15\}\end{array}$ \\
\hline & $20 \%$ & $\begin{array}{l}74.74 \\
\{1.70\}\end{array}$ & $\begin{array}{l}50.92 \\
\{3.09\}\end{array}$ & $\begin{array}{l}22.66 \\
\{4.45\}\end{array}$ & $\begin{array}{l}28.99 \\
\{2.18\}\end{array}$ & $\begin{array}{l}0.87 \\
\{0.48\}\end{array}$ & $\begin{array}{l}0.44 \\
\{0.09\}\end{array}$ \\
\hline \multirow[t]{4}{*}{$\begin{array}{l}\text { Kinetic Energy } \\
(\mathrm{N} \mathrm{m})\end{array}$} & $0 \%$ & $\begin{array}{l}13.85 \\
\{3.49\}\end{array}$ & $\begin{array}{l}3.59 \\
\{1.17\}\end{array}$ & $\begin{array}{l}7.66 \\
\{3.01\}\end{array}$ & $\begin{array}{l}8.79 \\
\{1.72\}\end{array}$ & $\begin{array}{l}0.08 \\
\{0.08\}\end{array}$ & $\begin{array}{l}0.13 \\
\{0.06\}\end{array}$ \\
\hline & $10 \%$ & $\begin{array}{l}13.26 \\
\{3.32\}\end{array}$ & $\begin{array}{l}3.84 \\
\{1.33\}\end{array}$ & $\begin{array}{l}7.44 \\
\{2.66\}\end{array}$ & $\begin{array}{l}10.31 \\
\{3.09\}\end{array}$ & $\begin{array}{l}0.07 \\
\{0.06\}\end{array}$ & $\begin{array}{l}0.12 \\
\{0.07\}\end{array}$ \\
\hline & $15 \%$ & $\begin{array}{l}11.73 \\
\{3.92\}\end{array}$ & $\begin{array}{l}3.76 \\
\{1.53\}\end{array}$ & $\begin{array}{l}6.22 \\
\{2.62\}\end{array}$ & $\begin{array}{l}9.85 \\
\{2.57\}\end{array}$ & $\begin{array}{l}0.09 \\
\{0.06\}\end{array}$ & $\begin{array}{l}0.16 \\
\{0.08\}\end{array}$ \\
\hline & $20 \%$ & $\begin{array}{l}11.75 \\
\{3.10\}\end{array}$ & $\begin{array}{l}3.40 \\
\{0.44\}\end{array}$ & $\begin{array}{l}7.62 \\
\{1.91\}\end{array}$ & $\begin{array}{l}9.24 \\
\{1.94\}\end{array}$ & $\begin{array}{l}0.10 \\
\{0.08\}\end{array}$ & $\begin{array}{l}0.17 \\
\{0.14\}\end{array}$ \\
\hline
\end{tabular}

Table 3: Statistically similar to male data $(\mathrm{p}>0.05)$, mean kinetic joint parameters $\{+/-\mathrm{sd}\}$ were calculated from female subject data $(\mathrm{n}=5)$ of which each were carrying a range of pack loads as percentages of body weight. 


\begin{tabular}{|l|l|l|l|l|}
\hline & $\begin{array}{l}\text { Maximum } \\
\text { Kinetic } \\
\text { Energy }\end{array}$ & $\begin{array}{l}\text { Minimum } \\
\text { Kinetic } \\
\text { Energy }\end{array}$ & $\begin{array}{l}\text { Maximum } \\
\text { Inertial } \\
\text { Moment }\end{array}$ & $\begin{array}{l}\text { Minimum } \\
\text { Inertial } \\
\text { Moment }\end{array}$ \\
\hline Pack Load & $p=0.4622$ & $p=0.5145$ & $p=0.6368$ & $p=0.5192$ \\
\hline Joint & $p=0.0001$ & $p=0.0001$ & $p=0.0001$ & $p=0.0001$ \\
\hline BMI & $p=0.1130$ & $p=0.7639$ & $p=0.0455$ & $p=0.0220$ \\
\hline
\end{tabular}

Table 4: Statistical results summarizing a three-way ANOVA comparison between the interactions of pack load, anatomical joint, and BMI. While accounting for joint and BMI, there appears to be little influence of the range of pack loads on the kinetic parameters ( $\mathrm{p}$ $>0.05)$. However, BMI does appear to be a potential predictor of joint inertial moments $(\mathrm{p}<0.05)$.

\section{Discussion}

The presented work provides a unique perspective on forensic gait biomechanics by investigating the influence of hidden pack weights on human motion. In addition, the study builds off of the novel application of the Gröbner Basis Theory as a streamlined approach to calculating the inverse dynamics associated with human limb and joint motion. The quantified approach demonstrates a potentially useful transition from joint displacement data to full kinematic and kinetic metrics, which may provide further gait characterization as signature motions identifying terrorist activities.

Although the presented results did not provide definitive biomechanical signatures of perturbed gait, the calculated values were similar to the lower limb joint kinematics and kinetics reported by other researchers during studies of walking. As ground reaction forces were neither measured nor incorporated here, inertial-based moments and energy provide only a partial comparison of the joint mechanics [29]. Previous reports indicated that normal walking speeds generated similar motion within the hip, knee, and ankle [30]. As example, mean peak knee flexion was similar $(\Delta \%=1.4 \%)$ between our study $\left(65.9^{\circ}\right)$ and that published previously $\left(65.0^{\circ}\right)$ [30]. In addition, walking speedbased energetics was not as comparable, but within orders of magnitude [31]. Mean peak positive inertial power normalized by body mass and determined at peak inertial moments at the coincident rotational velocities for the hip $(1.44 \mathrm{~W} / \mathrm{kg})$, knee $(2.19 \mathrm{~W} / \mathrm{kg})$, and ankle $(0.03 \mathrm{~W} / \mathrm{kg})$ here can be compared with those powers published for the hip $(0.4 \mathrm{~W} / \mathrm{kg})$, knee $(0.2 \mathrm{~W} / \mathrm{kg})$, and have shown that subjects walk with greater knee flexion [32-35] and longer stance-phase times [35-38]. These changes were likely due to the much larger loads carried with traditional packs as compared with the pack design and load levels in the present study (range of maximum load differences between this study, $\Delta \%$.

The primary strength of this study is in the generation of kinetic parameters through an inverse dynamics approach albeit without the use of force-measuring devices (load cells, force plate, etc.). The obvious limitations in the design of this study include the minimal range in the worn pack loads, pack design, small subject population, and minimal subject participation, i.e., only one male subject wore a pack of $20 \%$ BW. In response to this limitation, a future study has been approved by our IRB and is underway to incorporate up to 50 subjects each wearing much larger weighted packs. An additional limitation here includes the focus on only two-dimensional motion.
Although treadmill restricted gait is generally uni-directional, there are still out--of-plane motions that exist including pelvic swing and abducted/adducted motions. Compensation for these z-direction motions were made during the initial construction of the Gröbner bases by incorporating limb shortening as characterized during motion capture. The two-dimensional approach provided an initial validation of the analytical technique.

This work represents an initial effort in testing the overall objective of whether the measured and calculated biomechanical gait parameters are indeed sensitive to pack load perturbations. A future study has been approved for increasing the upper limits of the pack loads. The analytical protocol described here will be applied toward that gathered data in a continuing effort to forensically identify gait signatures. The implications of these and future findings will be used to minimize the on-going impact of suicide bombings by identifying individuals wearing such incendiary devices

\section{Acknowledgements}

The authors appreciate the active participation of the volunteer subjects. Author $\mathrm{AB}$ also acknowledges the contributions of the additional members of her Master's thesis committee: Lt. Col. Brian McBee and Dr. Amy Magnus. Funding for this project was provided by the Air Force through the SOO Task Number 18 and Topic Title: 3.2.2.2.4 Human Centric ISR Sensors (Grant\# AFIT-ENP-13-M-02) as well as the National Science Foundation (Grant\# HRD-1240734).

\section{References}

1. Hicks MH, Dardagan H, Bagnall PM, Spagat M, Sloboda JA (2011) Casualties in civilians and coalition soldiers from suicide bombings in Iraq, 2003-10: a descriptive study. Lancet 378: 906-914.

2. (2012) Iraq Body Count. The public record of violent deaths following the 2003 invasion of Iraq.

3. Adebisi SS (2008) Fingerprint Studies-The recent challenges and advancements: A literary review. Internet J Bio Anthro 2.

4. Karu K, Jain AK (1996) Fingerprint classification. Pattern Recog 29: 389-404.

5. Zhang R, Vogler C, Metaxas, D. Human gait recognition at sagittal plane. Image Vision Comput 25: 321-330.

6. Wechsler H (2007) Reliable face recognition methods: system design, implementation, and evaluation. New York, NY: Springer Press 25- 50.

7. Phillips PJ, Sarkar S, Robledo I, Grother P, Bowyer K (2002) The gait identification challenge problem: data sets and baseline algorithm. In Proceedings of the 16th International Conference on Pattern Recognition. 1: 385- 388.

8. Stevenage S, Nixon M, Vince K (1999) Visual analysis of gait as a cue to identity. Appl Cogn Psychol 13: 513-526.

9. Barclay CD, Cutting JE, Kozlowski LT (1978) Temporal and spatial factors in gait perception that influence gender recognition. Percept Psychophys 23: 145-152.

10. Pellecchia GL, Garrett GE (1997) Assessing lumbar stabilization from point-light and normal video displays of manual lifting. Percept Mot Skills 85: 931-937.

11. Rosenblum LD, Johnson JA, Saldaña HM (1996) Point-light facial displays enhance comprehension of speech in noise. J Speech Hear Res 39: 1159-1170.

12. Moeslund T, Granum E (2001) A survey of computer vision-based human motion capture. Comput Vis Image Underst 81: 231-268. 
Citation: Kohles SS, Barki A, Kendricks KD, Tuttle RF (2014) Biomechanical Analysis of Concealed Pack Load Influences on Terrorist Gait Signatures derived from Gröbner Basis Theory. Forensic Biomechanics 5: 104. doi:10.4172/2090-2697.1000104

Page 7 of 8

13. Barki A, Tuttle RF, Kendricks KD (2014) Lower limb joint angles defined by Groebner Basis Theory as an inverse dynamics approach. In preparation.

14. Mummolo C, Mangialardi L, Kim JH (2013) Quantifying dynamic characteristics of human walking for comprehensive gait cycle. J Biomech Eng 135: 91006.

15. Zhang R, Vogler C, Metaxas D (2007) Human gait recognition at sagittal plane. Image Vision Comput 25: 321-330.

16. Barki A (2013) An Inverse Kinematic Approach Using Groebner Basis Theory. MS Thesis, Air Force Institute of Technology, WPAFB, OH.

17. Kim W, Kim YH, Veloso AP, Kohles SS (2013) Tracking Knee Joint Functional Axes through Tikhonov Filtering and Plücker Coordinates. J Nov Physiother S4(1): 11732..

18. Kim K, Veloso AP, Joao F, Kohles SS (2013) Efferent Copy and Corollary Discharge Motor Control Behavior Associated with a Hopping Activity. J Nov Physiother 3: 1000167.

19. Arellano CJ, Layne CS, O'Connor DP, Scott-Pandorf M, Kurz MJ (2009) Does load carrying influence sagittal plane locomotive stability? Med Sci Sports Exerc 41: 620-627.

20. Center for Disease Control and Prevention. Healthy Weight - it's not a diet, it's a lifestyle!

21. Kendricks KD (2013) Using Groebner Basis Theory to Identify and Isolate Gait Signatures. In SOO Task Number 18 and Topic Title: 3.2.2.2.4 Human Centric ISR Sensors Report.

22. Kendricks KD, Fullenkamp MA, McGrellis R, Juhl J, Tuttle FR (2010) An Inverse Kinematic Mathematical Model Using Groebner Basis Theory for Arm Swing (and Leg Swing) Movement in the Gait Cycle. In Proceedings of the 2010 Military Sensing Symposia on Battlespace Acoustic and Magnetic Sensors. Balitmore, MD.

23. Kendricks KD, A Taylor, Tuttle RF, Kohles SS (2014) A Deterministic Model of Human Motion Based on Algebraic Techniques and a Sensor Network to Simulate Shoulder Kinematics. Int J Biomed Eng.

24. Buchberger B (2001) Grobner bases: A short introduction for systems theorists. In Computer Aided Systems Theory EUROCAST 2001: 1-19.

25. Lazard D (1983) Grobner bases, Gaussian elimination and resolution of systems of algebraic equations. Comput Algebra 162: 146-156.
26. Kohles SS, Gregorczyk KN, Phillips TC, Brody LT, Orwin IF, et al. (2007) Concentric and eccentric shoulder rehabilitation biomechanics. Proc Inst Mech Eng H 221: 237-249.

27. Kroemer KHE (1989) Engineering Anthropometry. Ergonomics 32: 767-784.

28. Winter DA (1990) Biomechanics and Motor Control of Human Movement (2nd edn), New York, NY: John Wiley \& Sons, Inc 11-139.

29. Dogan S, Manley PA, Vanderby R Jr, Kohles SS, Hartman LM, et al. (1991) Canine intersegmental hip joint forces and moments before and after cemented total hip replacement. J Biomech 24: 397-407.

30. Lewek MD, Osborn AJ, Wutzke CJ (2012) The influence of mechanically and physiologically imposed stiff-knee gait patterns on the energy cost of walking. Arch Phys Med Rehabil 93: 123-128.

31. Farris DJ, Sawicki GS (2012) The mechanics and energetics of human walking and running: a joint level perspective. J R Soc Interface 9: 110-118.

32 Attwells RL, Birrell SA, Hooper RH, Mansfield NJ (2006) Influence of carrying heavy loads on soldiers' posture, movements and gait. Ergonomics 49: 1527-1537.

33. Kinoshita H (1985) Effects of different loads and carrying systems on selected biomechanical parameters describing walking gait. Ergonomics 28: 1347-1362.

34. Quesada PM, Mengelkoch LJ, Hale RC, Simon SR (2000) Biomechanical and metabolic effects of varying backpack loading on simulated marching. Ergonomics 43: 293-309.

35. Silder A, Delp SL, Besier T (2013) Men and women adopt similar walking mechanics and muscle activation patterns during load carriage. J Biomech 46: 2522-2528.

36. Birrell SA, Haslam RA (2009) The effect of military load carriage on 3-D lower limb kinematics and spatiotemporal parameters. Ergonomics 52: 1298-1304.

37. Harman E, Han KH, Frykman P, Johnson M, Russell F (1992) The effects on gait timing, kinetics, and muscle activity of various loads carried on the back. Med Sci Sports Exerc 24: S129.

38. Wiese-Bjornstal DM, Dufek JS (1991) The effect of weightload and footwear on kinetic and temporal factors in level grade backpacking. J Hum Mov Studies 21: 167-181. 